\title{
Heterodoxia jurídica no sul global: desigualdade e direito contratual comparado ${ }^{1}$
}

\section{Legal heterodoxy in the global south: inequality and comparative contract law}

\author{
Kevin E. Davis ${ }^{2}$ \\ New York University School of Law (New York, NY, United States of America) \\ ORCID: https://orcid.org/0000-0002-9278-6439 \\ E-mail:davisk@mercury.law.nyu.edu
}

\begin{abstract}
Mariana Pargendler ${ }^{3}$
Escola de Direito de São Paulo da Fundação Getulio Vargas (São Paulo, SP, Brasil) ORCID: https://orcid.org/0000-0002-5837-7199 E-mail: mariana.pargendler@fgv.br
\end{abstract}

\section{Resuimo}

Existem diferenças entre o direito privado dos países em desenvolvimento e o direito dos países desenvolvidos? A literatura frequentemente oferece uma das seguintes respostas: ou o direito dos países em desenvolvimento é antiquado e ineficiente, exigindo modernização, ou é perfeitamente adequado do ponto de vista formal, mas carece de efetividade. O presente artigo busca questionar essas visões ao apresentar como os tribunais da África do Sul e da Colômbia, assim como os brasileiros, têm buscado incorporar preocupações distributivas nas decisões em matéria de direito contratual - fenômeno que denominamos de "heterodoxia contratual". $\mathrm{O}$ reconhecimento da heterodoxia contratual em países em desenvolvimento chama a atenção para as manifestações existentes, embora mais limitadas, do mesmo fenômeno em países desenvolvidos. Sugere-se que a desigualdade e a injustiça social persistentes minam as premissas que alicerçam a defesa do direito contratual ortodoxo, conduzindo a um renovado interesse pela heterodoxia contratual ao redor do mundo na atualidade.

\footnotetext{
${ }^{1}$ DAVIS, Kevin E.; PARGENDLER, Mariana. Heterodoxia jurídica no sul global: desigualdade e direito contratual comparado. Suprema: revista de estudos constitucionais, Brasília, v. 1, n. 1, p. 267-298, jan./jun. 2021.

${ }^{2}$ Beller Family Professor of Law da New York University School of Law (NYU). LLM pela Columbia Law School. Currículo: https://its.law.nyu.edu/facultyprofiles/index.cfm?fuseaction=profile.full_cv\&personid=22193.

${ }^{3}$ Professora Associada da Escola de Direito de São Paulo da Fundação Getúlio Vargas (FGV Direito SP). Coordenadora do Núcleo de Direito, Economia e Governança da FGV Direito SP. LL.M. e JSD (Doctor of the Science of Law) pela Yale Law School e Doutora em Direito pela Universidade Federal do Rio Grande do Sul. Currículo Lattes: https://lattes.cnpq.br/9266588617859978.
} 


\section{Palavras-chave}

Direito contratual; desigualdade; Direito Comparado; Direito e Desenvolvimento; heterodoxia jurídica.

\section{Surmário}

1. Introdução. 2. A ortodoxia contratual. 3. A heterodoxia contratual nos países em desenvolvimento. 4. Explicando a divergência. 5. Conclusão.

\section{Abstract}

Are there differences between the private laws of developed and developing countries? The literature typically offers one of two answers: the law of developing countries is either antiquated and inefficient, or perfectly adequate from a formal perspective, but plagued by difficulties in enforcement. This article seeks to challenge this view by demonstrating how courts in South Africa and Colombia, like their Brazilian counterparts, have sought to incorporate distributional considerations in the application of contract law - a phenomenon that we term "contract law heterodoxy." The recognition of contract heterodoxy in these developing countries highlights the existing, though more limited, instances of heterodoxy in the laws of developed countries. We suggest that persistent inequality and social injustice undermine the assumptions that support an orthodox approach to contract law, leading to a growing interest in contract heterodoxy around the world today.

\section{Keywords}

Contract law; inequality; comparative law; law and development; legal heterodoxy.

\section{Contents}

1. Introduction. 2. Contract orthodoxy. 3. Legal heterodoxy in developing countries.

4. Explaining divergence. 5. Conclusion. 


\section{Introdução}

Os campos do Direito Comparado e do Direito e Desenvolvimento não dedicam atenção suficiente às particularidades jurídicas de países em desenvolvimento. De um lado, é corrente a premissa de que o Direito dessas nações é antiquado e ineficiente, exigindo modernização. De outro, há o diagnóstico de que, ainda quando formalmente irretocável em sua versão "nos livros", há sérios problemas de efetivação (enforcement). A possibilidade de os países em desenvolvimento conceberem soluções jurídicas próprias, moldadas pelas peculiaridades de seu contexto econômico, social e institucional, tem recebido relativamente pouca atenção. Descuida-se, assim, do exame de inovações jurídicas, meritórias ou não, em países em desenvolvimento.

Explora-se aqui a ideia de que o Direito atual dos países em desenvolvimento com frequência se distingue dos contornos dominantes em países desenvolvidos e até mesmo daqueles historicamente prevalentes em sua tradição jurídica. Uma dessas diferenças é o recurso mais frequente a objetivos sociais ou distributivos na aplicação de institutos jurídicos fundamentais. A robusta literatura de Direito Constitucional Comparado sublinha como diversos países em desenvolvimento têm buscado promover a igualdade econômica mediante a interpretação constitucional (VERSTEEG, 2020, p. 2020). Porém, se nessa seara é bem conhecido e refletido o fenômeno do "populismo judicial"4 (VERSTEEG, 2020, p. 2055, tradução nossa) para utilizar aqui expressão crítica ao movimento -, a incorporação de objetivos distributivos em outros ramos do Direito em países em desenvolvimento é ainda pouco explorada. O presente artigo busca identificar e refletir sobre a incorporação explícita de objetivos distributivos no Direito Contratual, fenômeno que aqui denominamos heterodoxia contratual. ${ }^{5}$

A visão predominante na literatura internacional é a de que o Direito Contratual não difere substancialmente ao redor mundo, pois eventuais diferenças de rótulos dogmáticos habitualmente esconderiam semelhanças de função. Presume-se que as distinções tradicionais entre o Direito Contratual nos sistemas de civil law e common law estão diminuindo ou têm significado econômico limitado (PARGENDLER, 2018 , p. 145 , p. 149; SPAMANN, 2009, p. 1814-1815). Quando economistas

\footnotetext{
${ }^{4}$ No original, "judicial populism”.

${ }^{5}$ Contamos com rótulos "ortodoxo" e "heterodoxo" na tentativa de descrever as diferenças na legislação dos países em desenvolvimento de uma forma neutra com relação a seus méritos normativos. Críticos e defensores podem referir-se a esse fenômeno como "direito contratual populista" ou "direito contratual progressista", respectivamente. Além das preocupações com a desigualdade que enfocamos neste artigo, as diferenças no Direito Contratual nos países em desenvolvimento são indiscutivelmente mais amplas e também moldadas por outros fatores, como a instabilidade macroeconômica e os desafios na execução de contratos - tópicos que esperamos abordar em trabalhos futuros.
} 
neoinstitucionalistas e agências internacionais, como o Banco Mundial, buscam avaliar a qualidade das instituições contratuais ao redor do mundo, seus esforços concentram-se exclusivamente nos mecanismos de execução contratual (enforcement) (tais como o tempo e os custos dos processos judiciais, bem como a competência e a integridade dos tribunais), ignorando por completo as potenciais variações nos princípios e regras de Direito Contratual (WORLD BANK, 2020; PARGENDLER, 2017, p. 1719).

Neste trabalho, procuramos qualificar esse entendimento convencional ao apontar para a maior prevalência da heterodoxia contratual em alguns países em desenvolvimento relativamente ao observado naqueles que são desenvolvidos. Segundo a ortodoxia contratual dominante em nações desenvolvidas, os objetivos do Direito Contratual são promover a autonomia, a eficiência econômica ou a justiça da troca, sem cuidar da distribuição de recursos na sociedade - tarefa que, quando realizada por juízes, e não por legisladores, seria tanto ilegítima como ineficaz. De acordo com a visão ortodoxa, fins distributivos devem ficar a cargo exclusivamente do sistema fiscal (tributação e gastos públicos).

Por certo, há muito tempo a literatura nacional tem discutido se a abordagem substantiva dos tribunais brasileiros em relação às disputas contratuais é tanto peculiar como problemática para o desenvolvimento econômico (PARGENDLER, 2017). Economistas e sociólogos constataram, mediante a aplicação de questionários, especial preocupação dos juízes brasileiros com a "justiça social” na resolução de disputas contratuais (LAMOUNIER; SOUZA, 2002; PINHEIRO, 2002). Também nos anos 2000, renomados economistas publicaram trabalho que atribuía à "incerteza judicial" decorrente de "viés anticredor"7 o alto spread bancário praticado no País, bem como a ausência de um mercado de crédito de longo prazo (ARIDA; BACHA; LARA-RESENDE, 2005, tradução nossa).

Embora a existência de um viés anticredor tenha sido questionada por estudos teóricos e empíricos subsequentes (FALCÃO NETO; SCHUARTZ; ARGUELHES, 2006; SALAMA, 2017; YEUNG; AZEVEDO, 2015), trabalhos posteriores identificaram novas decisões heterodoxas, como aquelas em favor da revisão de contratos de compra e venda futura de soja verde diante do aumento do preço internacional do produto (REZENDE; ZYLBERSZTAJN, 2012). O apelo à função social do contrato como fundamento para posicionamentos jurisprudenciais

\footnotetext{
${ }^{6}$ No original, "Jurisdictional uncertainty".

${ }^{7}$ No original, "Anticreditor bias".
} 
heterodoxos tem suscitado fortes críticas no Brasil sob a perspectiva da análise econômica do Direito(TIMM, 2009), a qual também tem apontado o risco de potencial "efeito bumerangue" em detrimento do grupo que se busca favorecer (SALAMA, 2015). Aliás, ao reformar diversas normas do Código Civil para reiterar cânones clássicos da ortodoxia contratual, a Lei da Liberdade Econômica (Lei 13.874, de 20 de setembro de 2019) apenas pode ser compreendida como reação à abordagem heterodoxa prevalente nos tribunais brasileiros, embora as consequências concretas do novo diploma ainda permaneçam incertas.

Demonstra-se aqui que a heterodoxia contratual não constitui traço acidental ou exclusivo do Direito brasileiro. Ao contrário, trata-se de fenômeno comum a outros países em desenvolvimento com ordem constitucional que se pretende progressista e transformadora. Para tanto, oferecemos diversos exemplos de decisões das Cortes Constitucionais da África do Sul e da Colômbia que buscam explicitamente atingir objetivos distributivos em disputas contratuais, tais como a redução da desigualdade e a proteção de grupos desfavorecidos. Além disso, cotejamos esses achados com a literatura atual de Direito e Economia, segundo a qual a ausência de esforços distributivos eficazes pelo sistema fiscal justifica a consideração de critérios distributivos no Direito Privado (FENNELL; McADAMS, 2016; LISCOW, 2020).

Sugerimos que três fatores favorecem a heterodoxia contratual em nações em desenvolvimento, como o Brasil, a África do Sul e a Colômbia: (i) a saliência de questões distributivas em razão dos altos níveis de pobreza e desigualdade estrutural, inclusive em razão de fatores históricos como a escravidão e a exploração colonial; (ii) a insuficiência do sistema fiscal para reduzir de forma significativa e persistente as diferenças entre os grupos sociais; e (iii) a existência de uma ordem constitucional que busca reduzir as desigualdades. Esses fatores reduzem a força do argumento institucional contra a consideração de objetivos distributivos no Direito Contratual comparativamente ao que ocorre nas jurisdições desenvolvidas e fortalece o argumento em favor da legitimidade de objetivos distributivos. Embora os potenciais usos do Direito Contratual para mitigar a desigualdade tenham sido objeto de acalorado debate acadêmico, conforme detalhado a seguir, a dimensão comparativa desse debate tem sido negligenciada, especialmente com relação aos países em desenvolvimento, onde a desigualdade é uma preocupação especialmente premente.

Antes de prosseguir, cabem algumas ressalvas. Não afirmamos que a heterodoxia jurídica prevalece em todos os países em desenvolvimento ou mesmo que ela é dominante nas jurisdições aqui referidas; de fato, não parece ser este o caso. Também não sustentamos que o regime contratual heterodoxo efetivamente atinge os objetivos 
de equidade pretendidos; ao contrário, abordagens heterodoxas podem não apenas ser ineficientes, mas também ter efeitos contrários aos esperados. Além disso, optamos por excluir do escopo deste trabalho a disciplina jurídica dos contratos de trabalho, visto que já são conhecidas pela literatura as variações entre o Direito Trabalhista de diferentes países em razão de objetivos distributivos (AHLERING; DEAKIN, 2007; BOTERO et al., 2004; HALL; SOSKICE, 2001).

O restante da exposição será estruturado da seguinte forma: a primeira seção define a ortodoxia contratual e aponta a sua relativa preponderância no Direito dos Estados Unidos e da Europa continental. A segunda seção apresenta exemplos mais robustos de heterodoxia contratual na África do Sul e na Colômbia, que se assemelham aos fenômenos já identificados na literatura brasileira acima aludida. A terceira seção busca explicar e avaliar as divergências observadas. Por fim, concluímos que a conjetura de crescente desigualdade global estimulará a renovação do interesse por abordagens heterodoxas de Direito Contratual também em países desenvolvidos.

\section{A ortodoxia contratual}

Embora haja profundas discordâncias sobre o assunto, a visão ortodoxa é a de que o Direito Contratual, especialmente quando aplicado pelos juízes, não se preocupa e não deve se preocupar com a distribuição da riqueza na sociedade (COLLINS, 1992; SCOTT, 2020; TUSHNET, 2020). Liberais e libertários defendem a orientação do Direito Contratual em torno do valor da autonomia individual, de modo a permitir que os indivíduos decidam como se vincular juridicamente ou, de forma mais ampla, lhes possibilite buscar suas próprias concepções do bem em colaboração com outros (BARNETT, 1986; BENSON, 2019; DAGAN; HELLER, 2017; FRIED, 1981; RIPSTEIN, 2009). Os estudiosos de Direito e Economia sustentam que o Direito Contratual deve promover a eficiência econômica, facilitando trocas mutuamente benéficas segundo o critério de Pareto (TREBILCOCK, 1993, p. 15-17). Por fim, os juristas e os filósofos afiliados à tradição aristotélica concentram-se no papel do Direito Contratual de preservar a distribuição de riqueza existente (presumivelmente justificada), preocupandose com a justiça substantiva das trocas contratuais (GORDLEY, 1981). Conquanto essas tradições intelectuais sejam nitidamente distintas entre si, todas excluem objetivos distributivos do âmbito do Direito Contratual.

$\mathrm{Na}$ prática, a distinção entre o que chamamos de abordagens ortodoxas e heterodoxas de Direito Contratual denota um espectro com diferentes gradações, e 
não uma divisão binária. Um sistema jurídico pode adotar acolher soluções ortodoxas com relação a determinados tipos de contratos, mas não a outros, ou atribuir pesos distintos a considerações distributivas, conforme se passa a demonstrar. Autores ligados à corrente de critical legal studies, movimento de esquerda que agitou o debate acadêmico norte-americano nos anos 1970 e 1980, não apenas defendiam a atenção a questões distributivas do ponto de vista normativo, como questionavam a leitura de que o Direito Contratual então vigente era estritamente ortodoxo e despido de preocupações solidaristas (KENNEDY, 1976; KENNEDY, 1982; UNGER, 1983).

Nos últimos anos, autores norte-americanos, incluindo adeptos do movimento de Direito e Economia, voltaram a contestar a exclusão de considerações distributivas do Direito Privado em geral e do Direito Contratual em particular (BAGCHI, 2008; FENELL; McADAMS, 2016; LISCOW, 2014; VAN LOO, 2019). Tal movimento representa um renascimento dos debates normativos que floresceram durante as décadas de 1970 e 1980 (ACKERMAN, 1971; KRONMAN, 1980), mas que posteriormente morreram juntamente com o interesse em desenvolver o Direito Contratual como parte do "direito dos pobres" (FLEMING, 2014, p. 1836, tradução nossa). Trata-se de um resgate das dimensões distributivas dos diferentes ramos do Direito, tão caras ao "primeiro movimento de Direito e Economia" (HOVENKAMP, 1990, tradução nossa) vigente dos anos 1880 até o New Deal, mas posteriormente abandonadas com a ascensão da Escola de Chicago (HOVENKAMP, 1990). A tendência observada no Direito Contratual integra um movimento mais amplo que busca ampliar os objetivos normativos a serem perseguidos pelas diversas áreas jurídicas, destoando assim da tradicional premissa de "modularidade" e especialização funcional há muito dominante em trabalhos de Direito e Economia (PARGENDLER, 2020b, p. 970-974).

Trabalhos recentes contestam diretamente a visão ortodoxa de que a política fiscal é a forma mais eficaz e legítima de atingir objetivos distributivos nos Estados Unidos (EUA). Zachary Liscow (2020) aponta que a resistência inata do público em geral à distribuição mediante política fiscal, justaposta à sua relativa receptividade à distribuição por meio de outras políticas públicas, requer o abandono da abordagem ortodoxa de confiar exclusivamente na política fiscal fins de distribuição de riqueza. Além disso, Helen Hershkoff $(2010,2013)$ identificou fundamentos teóricos e dogmáticos para interpretar-se a common law à luz dos direitos socioeconômicos positivos estabelecidos nas constituições estaduais norte-americanas.

\footnotetext{
${ }^{8}$ No original, "Law of the poor".

${ }^{9}$ No original, "first law and economics movement".
} 
No entanto, as propostas heterodoxas têm tido pouco impacto na dogmática contratual norte-americana até o momento. O Direito Contratual dos EUA é tido como bastante ortodoxo. Os institutos que podem ser utilizados para proteger a parte mais fraca são acionados sobretudo quando essa tem menos informações ou está sendo coagida pela parte contrária, ou quando o negócio se desvia significativamente das noções prevalentes de troca justa (THE AMERICAN LAW INSTITUTE, 2019). Não se costuma considerar se o polo mais fraco da relação está em desvantagem comparativamente à sociedade como um todo ou invocar expressamente preocupações com a justiça social.

Há, contudo, exemplos históricos isolados de heterodoxia contratual nos EUA. A decisão canônica aplicando a doutrina de unconscionability $^{10}$ no caso contratual Williams v. Walker-Thomas (350 F.2d 445 (D.C. Cir. 1965)) foi descrita pelo juiz Wright como parte do "direito dos pobres" (FLEMING, 2014, p. 1836, tradução nossa), sendo preocupações com a "discriminação de raça e classe" 12 igualmente manifestas em sua decisão que reconheceu uma garantia implícita de habitabilidade em contratos de locação residencial no caso Javins v. First National Realty (428 F.2d. 1071 (D.C. Cir., 1970), tradução nossa).

Verifica-se um longo histórico de leis estaduais nos EUA que impõem moratórias sobre a execução de direitos de crédito, especialmente durante períodos de crise econômica e particularmente em benefício de agricultores (FRIEDMAN, 2019, p. 229-230; ALSTON, 1984). A Suprema Corte reconheceu a constitucionalidade de moratória imposta durante a Grande Depressão, entendendo que "a emergência econômica que ameaçava a perda de casas e terras que forneciam aos seus possuidores o abrigo e meios de subsistência necessários"13 era uma razão relevante para a promulgação da lei (Home Building er Loan Ass'n v. Blaisdell, 290 U.S. 398 (1934), tradução nossa). Há também exemplos recentes de legislação contratual com efeitos distributivos significativos, ainda que esse não tenha sido o seu propósito declarado (VAN LOO, 2019), como o Credit Card Accountability Responsibility, and Disclosure Act of 2009, que, segundo estimativas, economizou aos consumidores US\$ 11,9 bilhões por ano nos dois primeiros anos após sua entrada em vigor (AGARWAL et al., 2015).

\footnotetext{
${ }^{10}$ Em português, "abusividade".

${ }^{11}$ No original, "law of the poor".

${ }^{12}$ No original, "racial and class discrimination".

${ }^{13}$ No original, "the economic emergency which threatened 'the loss of homes and lands which furnish those in possession the necessary shelter and means of subsistence”.
} 
A ortodoxia também é predominante no Direito Contratual da Europa continental. As proteções ao consumidor no direito europeu podem ser interpretadas como resposta aos vieses comportamentais do consumidor, à informação assimétrica ou à injustiça da troca, sendo compatíveis com uma abordagem ortodoxa do Direito Contratual, embora frequentemente criticadas por estudiosos de Direito e Economia (BAR-GILL; BEN-SHAHAR, 2013, p. 109-110). Vários Estados europeus reconhecem a eficácia horizontal dos direitos fundamentais nas relações privadas, assim como o Tribunal de Justiça da União Europeia (TJUE) (CHEREDNYCHENKO; REICH, 2015), mas a utilização da constitucionalização do Direito Contratual permanece relativamente restrita comparativamente aos países em desenvolvimento examinados na seção seguinte.

Há, porém, maior apoio ao discurso heterodoxo na doutrina europeia relativamente à norte-americana. Diversos renomados juristas europeus lançaram um manifesto contra as iniciativas de harmonização da Comissão Europeia precisamente por considerá-las insuficientemente preocupadas com a justiça social (STUDY GROUP ON SOCIAL JUSTICE IN EUROPEAN PRIVATE LAW, 2004), ao mesmo tempo em que estudiosos do Direito Contratual dos EUA consideram excessiva a preocupação com a justiça social no direito europeu (CARUSO, 2013).

Mais recentemente, a pandemia da COVID-19 conduziu não apenas à adoção de moratórias sobre despejos de locatários residenciais em várias cidades e estados nos Estados Unidos, mas também levou a novas manifestações heterodoxas no Direito Contratual na Europa. A lei alemã sobre a "mitigação das consequências da pandemia da COVID-19"14 permite que o consumidor não realize o pagamento por serviços essenciais contínuos quando não puder arcar com o custo sem arriscar sua subsistência e a de seus dependentes (BRUNOTTE; ELSAß, 2020). O mesmo direito também é estendido às microempresas, desde que seu exercício não coloque em risco a subsistência do credor, a subsistência razoável dos seus dependentes ou a base econômica do negócio, caso em que o devedor pode tentar resolver o contrato (BRUNOTTE; ELSAß, 2020). Ao vincular os direitos contratuais à situação econômica particular das partes - e não à justiça da troca -, a lei especial alemã reflete nova manifestação de heterodoxia contratual em uma jurisdição desenvolvida em tempos de crise econômica significativa, ainda que de forma temporária.

${ }^{14}$ No original, "Gesetz zur Abmilderung der Folgen der COVID-19-Pandemie im Zivil-, Insolvenz- und Strafverfahrensrecht". 


\section{A heterodoxia contratual nos países em desenvolvimento}

Nesta seção, serão descritos casos em que o Direito Contratual da África do Sul e da Colômbia divergem da concepção ortodoxa. Apresenta-se uma coleção eclética de ilustrações: as disputas examinadas abarcam desde contratos de compra e venda de terras e de seguro a contratos de fornecimento de água. Esses exemplos revelam que a heterodoxia do Direito Contratual fez importantes incursões nos sistemas jurídicos desses países, tal como ocorre no Brasil. Nesses contextos, tal como aqui, há tensões e conflitos entre abordagens ortodoxas e heterodoxas. As diferenças a serem tratadas concernem aos graus de ortodoxia e de heterodoxia, lembrando-se que o estudo do Direito Comparado cuida justamente de diferenças relativas, e não absolutas (WHITMAN, 2004, p. 1163).

\section{A. África do Sul}

A África do Sul é talvez o principal exemplo de jurisdição que adotou recentemente uma abordagem heterodoxa impulsionada pela incorporação de princípios constitucionais no Direito Contratual. A aplicação horizontal dos princípios constitucionais nas relações privadas é expressamente exigida pela Constituição sulafricana, que declara: "ao desenvolver a common law ou o direito consuetudinário, toda corte, tribunal ou fórum deve promover o espírito, finalidade e objetos da Bill of Rights", Constitution of the Republic of South Africa, 1996, \$39(2), tradução nossa). ${ }^{15}$

Em uma série de decisões célebres, a Corte Constitucional da África do Sul determinou que tanto os princípios do Direito Contratual quanto as decisões sobre a aplicação de cláusulas contratuais específicas devem estar de acordo com os valores constitucionais (Barkhuizen v. Napier [2007] ZACC 5, \$30; Everfresh Market Virginia (Pty) Ltd v. Shoprite Checkers (Pty) Ltd (CCT 105/10) [2011] ZACC $30, \$ 48)$. Tal análise pode implicar o afastamento da tradição colonial representada pelo direito inglês, romano e holandês (Everfresh, $\$ 23$ (Yacoob J.) e $\$ 71$ (Moseneke DCJ)). Entre esses valores constitucionais está o ubuntu, um conceito africano que enfatiza a natureza comunitária da sociedade e abrange as ideias de "humanidade, justiça social e equidade"16, assim como os "valores centrais de solidariedade do grupo, compaixão, respeito, dignidade humana, respeito a normas básicas e unidade coletiva” ${ }^{17}$ (Everfresh, $\$ 71$, tradução nossa).

\footnotetext{
${ }^{15}$ No original, "when developing the common law or customary law, every court, tribunal or fórum must promote the spirit, purport and objects of the Bill of Rights."

${ }^{16}$ No original, "humaneness, social justice and fairness".

${ }^{17}$ No original, "the key values of group solidarity, compassion, respect, human dignity, conformity to basic norms and collective unity".
} 
No caso Paulsen and Another v. Slip Knot Investments 777 (Pty) Limited ([2015] ZACC 5), a Corte Constitucional considerou que os limites ao princípio da liberdade contratual devem ser moldados à luz das realidades socioeconômicas, que incluem grandes níveis de desigualdade e pobreza. O recurso dizia respeito ao alcance do antigo instituto do in duplum, uma regra que limita os juros sobre dívidas em atraso a um montante igual ao valor da dívida principal. No caso Paulsen (\$96), a questão controvertida era se a regra in duplum se aplicava aos juros acumulados após a instauração do processo judicial, mas antes da data do julgamento. Em uma decisão de 1997, chamada Oneanate, a Suprema Corte de Apelação da África do Sul havia decidido que a regra in duplum deveria ser suspensa durante a pendência do litígio (Standard Bank of South Africa Ltd. v. Oneanate Investments (Pty) Ltd (in liquidation) [1997] ZASCA 94).

Os devedores no caso Paulsen eram fiadores de um incorporador imobiliário que havia inadimplido dívida de $\mathrm{R} \$ 12$ milhões. O contrato de empréstimo especificava que os juros deveriam ser acumulados à taxa de $3 \%$ ao mês. Aplicandose a tradicional regra in duplum, a quantia devida ao credor estaria limitada a R\$ 24 milhões. Já sob a versão mais restrita da regra acolhida em Oneanate, o credor teria direito a R\$ 72 milhões.

Em uma decisão dividida, a Corte Constitucional decidiu restabelecer a tradicional regra in duplum. No voto vencedor, o juiz Madlanga consignou que a decisão no caso Oneanate havia ignorado o risco de que a modificação da regra prejudicaria os devedores e inibiria seu direito constitucional de acesso aos tribunais. Argumentou da seguinte forma: "os devedores, apesar da crença genuína de que tenham uma defesa válida, podem ser levados a optar por um acordo do que enfrentar uma quantia de juros financeiramente ruinosa que começará a acumular-se a partir do início do processo judicial” ${ }^{18}$ (Paulsen, $\$ \$ 63-64$, tradução nossa).

É bem verdade que o Madlanga reconheceu a existência de considerações de política pública concorrentes. Em particular, a regra tradicional encorajaria os devedores a prolongar o litígio aduzindo defesas frívolas ou empregando outras táticas de retardamento. Tal resultado poderia suscitar uma preocupação constitucional caso levasse os credores a abandonar as pretensões contra os devedores inadimplentes porque o valor do crédito seria corroído pela inflação (Paulsen, $₫$ 65). Por outro lado, porém, havia a possibilidade de os credores se protegerem cobrando taxas de juros relativamente altas, evitando empréstimos a devedores

\footnotetext{
${ }^{18}$ No original, "debtors, despite a genuinely held belief that they have a valid defence, may sooner opt to settle a claim than face the potentially financially ruinous interest that would again commence to pile up once court process was served".
} 
de alto risco e litigando rapidamente (Paulsen, $\$ \$ 81-85$ ). Segundo Madlanga, os custos do litígio prolongado prejudicariam mais os devedores comparativamente aos credores porque, embora os Paulsen parecessem ser empresários sofisticados, os devedores em geral eram mais propensos a ser financeiramente vulneráveis (Paulsen, \$ 69). Considerando "as realidades socioeconômicas da África do Sul" ${ }^{19}$, anota Madlanga, "para os diversos consumidores de crédito que se localizam no lado errado das vastas disparidades de capital no país, juros astronômicos podem significar a diferença entre sobrevivência econômica e ruína financeira completa" ${ }^{20}$ (Paulsen, $\$ 66$, tradução nossa). E acrescenta: "embora em alguns casos os credores possam perder dinheiro para a inflação durante o litígio, é improvável que isso tenha os mesmos efeitos catastróficos para o credor comparativamente aos efeitos da acumulação desenfreada de juros sobre o devedor" - sendo que "a escolha entre os dois seria fácil para mim”21 (Paulsen, $\$ 66$, tradução nossa).

O juiz Madlanga deixou claro que estava particularmente preocupado com os devedores afetados pelo apartheid que permaneciam financeiramente vulneráveis ou estavam apenas saindo das estatísticas dos financeiramente vulneráveis. Observa o juiz que, "para a nossa democracia ser significativa, é apenas adequado que aqueles previamente afetados pelo racismo e apartheid, confinados às margens da sociedade e despidos de dignidade e autoestima, possam também ingressar no terreno de atividade econômica significativa e substancial”22 (Paulsen, $\$ 75$, tradução nossa). Tal resultado, segundo o juiz, "não pode ser atingido sem financiamento", de modo que "o tipo de juros ao qual Oneanate expõe o nosso sistema jurídico é deletério ao necessário avanço econômico"23 (Paulsen, $\$ 75$, tradução nossa). Dessa forma, decidiu-se aplicar a regra do in duplum para limitar o crédito devido a R\$ 24 milhões.

Os princípios constitucionais também informam a interpretação das regras legais incidentes sobre cláusulas contratuais específicas. O exemplo mais proeminente

\footnotetext{
${ }^{19}$ No original, "We need to look at South Africa's socio-economic realities".

${ }^{20}$ No original, "To many credit consumers, who fall on the wrong side of this country's vast capital disparities, astronomical interest may mean the difference between economic survival and complete financial ruin."

${ }^{21}$ No original, "While in some cases creditors may lose money to inflation during litigation, this is very unlikely to have the same catastrophic effect on the creditor compared to what the accumulation of run-away interest will have on the debtor. If I were to be forced to make a choice between the two, it would be an easy one for me."

${ }^{22}$ No original, "It cannot be plausibly gainsaid that for our democracy to be meaningful, it is only fitting that those previously denigrated by racism and apartheid, confined to the fringes of society and stripped of dignity and self-worth must also enter the terrain of meaningful, substantial economic activity".

${ }^{23}$ No original, "Entrepreneurship and the economic advancement of those with no history of being financially resourced must be given room to take root and thrive. This can hardly happen without finance. The sort of interest to which Oneanate exposes our legal system is deleterious to this necessary economic advancement".
} 
é Botha v. Rich N.O., caso atinente aos direitos dos compradores de terras que realizam o pagamento em prestações (Botha and Another v. Rich NO and Others [2014] ZACC 11). O Alienation of Land Act 1981 autorizou um comprador que havia pago mais de 50\% do preço de compra a exigir que o título fosse registrado em seu nome, desde que fosse instituída hipoteca em favor do vendedor para garantir as obrigações remanescentes do comprador (Act 68 of 1981, s. 27(1)). A questão central em Botha era a seguinte: e se o vendedor não atendesse à exigência de transferência? Um comprador que havia inadimplido o pagamento das parcelas após pagar mais de 50\% do preço de compra só tinha direito a resolver o contrato e recuperar o valor que havia pago, ou poderia optar por exigir o cumprimento específico da obrigação de registrar a transferência? A lei mencionava a possibilidade de resolução e restituição, mas era silente sobre a execução específica (Alienation of Land Act 1981, ss. 27(3), 28(1)).

No caso Botha, a Corte decidiu que o comprador tinha direito à execução específica do direito à transferência, desde que pagasse as parcelas atrasadas e os valores devidos ao município. A Corte provavelmente poderia ter chegado a esse resultado apenas com base nos princípios gerais de interpretação. No entanto, o Tribunal se esforçou para vislumbrar uma questão constitucional, observando que sua decisão foi motivada pelo dever constitucional de promover o espírito e fins do Bill of Rights (Botha, $\$ \$ 23,28$ ). Apontou a Corte que o Alienation of Land Act foi promulgado para proteger os compradores a prestações, após o colapso de várias empresas de desenvolvimento municipal nos anos 1970 (Botha, $\$ \$ 30-31$ ). Diferentemente de outras decisões, a Corte deixou de consignar que, no contexto sul-africano, os adquirentes de imóveis a prestações tendem a ser relativamente pobres (Sarrahwitz v. Maritz N.O. and Another [2015] ZACC 14 82, juízes Cameron e Froneman).

As preocupações com a desigualdade também influenciaram a abordagem da Corte Constitucional da África do Sul em relação à aplicação de cláusulas contratuais. Do ponto de vista técnico, a Corte não confronta as cláusulas contratuais diretamente com as normas constitucionais, mas avalia as cláusulas contratuais à luz da ordem pública, que por sua vez são moldadas tanto por valores constitucionais como por princípios gerais do Direito como razoabilidade e justiça. A Corte Constitucional decretou que o relativo poder de barganha das partes do contrato em questão deve ser considerado para determinar se as cláusulas contratuais violam a ordem pública, declarando ser este "um princípio importante em uma sociedade tão desigual como a nossa" ${ }^{24}$ (Napier v. Barkhuzen, 2006 (4) SA 1 (SCA), \$59, tradução nossa). Tal abordagem contrasta com aquela adotada em casos como Paulsen, nos quais o tribunal ignorou o fato de as partes que buscavam proteção serem atores comerciais de peso.

${ }^{24}$ No original, "This is an important principle in a society as unequal as ours". 
A Corte Constitucional da África do Sul continua a enfrentar os desafios na utilização do Direito Contratual para promover a igualdade. Embora a maioria dos membros da Corte pareça estar convencida da legitimidade desse tipo de exercício, subsistem sérias questões sobre até que ponto estão dispostos a se afastar da ortodoxia. Observam-se preocupações contínuas sobre como identificar com precisão as partes desfavorecidas e como garantir que os benefícios potenciais das decisões não sejam revertidos por mudanças nas práticas contratuais. Todas essas questões foram levantadas, mas não necessariamente resolvidas, no caso BEADICA $231 \mathrm{CC}$ and Others v. Trustees for the time being of the Oregon Trust and Others $(\$ 15)$.

Nesse caso, o juiz permitiu que um conjunto de franqueados exercesse opções para renovar seus contratos de locação, não obstante tivessem descumprido a exigência contratual de notificar a contraparte sobre a sua intenção de exercer a opção mais de seis meses antes do termo contratual. Os franqueados eram empresas de propriedade negra e haviam adquirido seus negócios como parte de uma "operação de empoderamento econômico negro” ${ }^{25}$ financiada pelo National Empowerment Fund, um órgão público encarregado por lei de facilitar "a reparação da desigualdade econômica que resultou da injusta discriminação passada contra grupos historicamente desavantajados”26 (National Empowerment Fund Act, Act No 105 of 1998, \$ 3, tradução nossa). O juiz observou que a iniciativa de empoderamento sofreria golpe relevante se o contrato de locação fosse extinto (BEADICA, $\$ 39)$, julgando ser uma sanção desproporcional $(B E A D I C A, \$ 42)$. Invocou diferentes considerações de política pública que, por um lado, buscam promover a segurança jurídica e, por outro lado, pretendem infundir o Direito Contratual com boa-fé, justiça e valores constitucionais como o ubuntu.

A decisão do caso BEADICA foi revertida em sede de apelação (Trustees for the Time Being of Oregon Trust v. BEADICA 231 CC and Others (74/2018) [2019] ZASCA 29 [Oregon Trust]), sendo o novo resultado confirmado por uma decisão dividida da Corte Constitucional. Uma maioria de sete juízes determinou que as cláusulas de renovação foram escritas em linguagem simples e acessível a uma pessoa comum, de modo que os franqueados não conseguiram satisfazer seu ônus de mostrar que sua aplicação seria irrazoável (BEADICA, \$\$ 93-95).

Escrevendo para a maioria, a juíza Theron refutou fortemente a ideia de que a aplicação de uma cláusula contratual violaria o direito constitucional à igualdade apenas porque prejudicaria um membro de um grupo historicamente desfavorecido.

\footnotetext{
${ }^{25}$ No original, "black economic empowerment transaction".

${ }^{26}$ No original, "the redressing of economic inequality which resulted from the past unfair discrimination against historically disadvantaged persons".
} 
Concluiu que a recusa em fazer cumprir o pactuado lesaria, em vez de ajudar, a causa da igualdade, pois as partes contratantes responderiam a tal regime ajustando outras cláusulas de seus contratos com membros de grupos desfavorecidos, ou recusando-se a contratar com eles por completo. Como veremos adiante, essa preocupação com os efeitos futuros de uma decisão heterodoxa com relação ao mesmo grupo de pessoas que se busca favorecer ecoa uma objeção recorrente à heterodoxia contratual entre estudiosos do Direito.

Já os dois votos vencidos sustentaram haver provas suficientes de que os franqueados eram relativamente pouco sofisticados e em uma posição de poder de barganha desigual em comparação com os franqueadores, de modo que a aplicação do regramento contratual nessas circunstâncias violaria a boa-fé, a ordem pública e o ubuntu. A opinião da maioria, entretanto, traça limites importantes para a heterodoxia no Direito Contratual sul-africano.

\section{B. Colômbia}

O Tribunal Constitucional da Colômbia tem recorrido expressamente aos direitos fundamentais - tais como o direito a um mínimo existencial, saúde, moradia, dignidade humana e igualdade - na resolução de disputas contratuais envolvendo partes consideradas fracas e vulneráveis perante empresas privadas que prestam serviços públicos, tais como serviços de saúde ou fornecimento de água ou energia. A Constituição colombiana expressamente reconhece que os "serviços públicos são inerentes à finalidade social do Estado" e busca a sua "prestação eficiente a todos os habitantes do território nacional" ${ }^{27}$, a qual pode se dar diretamente pelo Estado ou por indivíduos ou grupos privados, sob regulação, controle e monitoramento estatal (Constituição da Colômbia, art. 365). Ainda segundo o texto constitucional, a lei deve regular a prestação de serviços públicos levando em conta os critérios de custo, solidariedade e redistribuição de renda (Constituição da Colômbia, art. 367). Não obstante a ausência de previsão legal, as decisões da Corte Constitucional têm intervindo em contratos relativos à prestação de serviços públicos para proteger partes especialmente desavantajadas em nome dos princípios constitucionais. Enquanto algumas dessas decisões parecem produzir resultados heterodoxos, outras alcançam resultados relativamente convencionais com base em argumentos que destacam a vulnerabilidade de uma das partes e os direitos sociais.

\footnotetext{
${ }^{27}$ Cf. a íntegra no original: "Artículo 365. Los servicios públicos son inherentes a la finalidad social del Estado. Es deber del Estado asegurar su prestación eficiente a todos los habitantes del territorio nacional”.
} 
Os casos contratuais normalmente chegam ao Tribunal Constitucional da Colômbia mediante o mecanismo processual da tutela, um tipo de ação garantido pela Constituição para proteger os direitos fundamentais contra as autoridades públicas, bem como contra as partes privadas em circunstâncias excepcionais definidas por lei (Constituição da Colômbia, art. 86). Enquanto as disputas de Direito Contratual são geralmente sujeitas à jurisdição e recursos ordinários, a tutela pode ser invocada por "sujeitos sob proteção especial" 28 , tais como idosos, doentes, menores, deficientes, mulheres chefes de família e pessoas que ganham menos de um salário mínimo (BAHAMÓN, 2016, p. 236, tradução nossa). As disputas contratuais que possam afetar os direitos fundamentais, como a vida, a saúde ou o mínimo existencial estão, portanto, sujeitas a pleitos em sede de tutela e revisão constitucional (BAHAMÓN, 2016, p. 239). A jurisprudência da Corte em matéria de Direito Contratual tem-se concentrado principalmente em contratos de seguros e de fornecimento de serviços públicos.

Em uma decisão de 2005, a Corte Constitucional da Colômbia considerou que a recusa de uma seguradora privada de saúde em renovar um contrato, embora geralmente admissível, violou o direito constitucional à saúde, dadas as circunstâncias do caso. $\mathrm{O}$ autor era uma pessoa idosa com múltiplas doenças que exigiam tratamento médico urgente, e o contrato de seguro saúde em questão estava em vigor há mais de quatro anos. A Corte rejeitou o argumento de que o direito social à saúde se aplicaria exclusivamente contra a estrutura de seguridade social oferecida pelo Estado, concluindo que "o objeto do contrato tem relação inseparável com relação aos efeitos do direito constitucional à saúde, razão pela qual a interpretação do alcance das cláusulas contratuais está submetida, em todo caso, à necessidade de garantir o exercício certo desse direito" ${ }^{29}$ (Corte Constitucional da Colômbia, Sentencia T-724/05, 8 jul. 2005, tradução nossa).

Em uma decisão posterior de 2011, o Tribunal decidiu que uma seguradora de saúde não poderia extinguir um contrato pelo não pagamento continuado do prêmio mensal quando o segurado fosse soropositivo, citando os direitos fundamentais à vida digna, à saúde, à integridade pessoal, à seguridade social e à igualdade (Corte Constitucional da Colômbia, Sentencia T-811-11,27 out. 2011). Concluiu que, embora o paciente estivesse recebendo tratamento pelo sistema de saúde pública padrão da

\footnotetext{
${ }^{28}$ No original, "sujetos de especial protección":

${ }^{29}$ No original, "el objeto de ese contrato tiene una relación inescindible con la eficacia del derecho constitucional a la salud, por lo que la interpretación del alcance de las cláusulas contractuales está supeditada, en todo caso, a la necesidad de garantizar el ejercicio cierto de ese derecho".
} 
Colômbia, a questão relevante era o abuso da seguradora como a parte dominante do contrato (Corte Constitucional da Colômbia, Sentencia T-811-11, 27 out. 2011, p. 8).

Em 2019, o Tribunal Constitucional da Colômbia reverteu sua jurisprudência anterior para, considerando os direitos fundamentais, limitar a possibilidade de negativa da cobertura pela falha de informação do segurado quanto a condições preexistentes. Decidiu-se que uma seguradora só pode negar a cobertura se provar a má-fé do segurado em não revelar a condição, bem como o nexo causal entre a condição preexistente e o evento médico em questão, impondo à seguradora o ônus de solicitar históricos médicos ou exames. Além de recorrer ao princípio pro consumatore nos contratos de adesão, a Corte também fundamentou seu julgamento na "proteção do direito fundamental ao mínimo existencial das pessoas em situação de incapacidade ou fragilidade manifesta" ${ }^{30}$ (Corte Constitucional da Colômbia, Sentencia T-027-19, 30 jan. 2019, tradução nossa).

As preocupações com a desigualdade e a vulnerabilidade econômica no Direito Contratual colombiano não se limitam aos contratos de seguro-saúde. No mesmo julgamento, a Corte Constitucional também considerou que a ausência de revelação sobre problema de saúde preexistente não constitui razão suficiente para a negativa de cobertura ao parceiro sobrevivente em caso de contrato de seguro de vida (Corte Constitucional da Colômbia, Sentencia T-027-19, 30 jan. 2019). Havia um argumento bastante ortodoxo para manter a cobertura do segurado, pois o formulário usado na contratação não apresentava qualquer espaço para a listagem de problemas de saúde preexistentes. Ainda assim, a opinião da Corte atribuiu grande relevância às circunstâncias particulares do caso. Tendo perdido a renda de seu parceiro, a beneficiária corria o risco de perder sua casa devido ao não pagamento da hipoteca. Assim, o tribunal também fundamentou sua decisão no direito à moradia e a um mínimo existencial (Corte Constitucional da Colômbia, Expediente T-6.579.174). Discorreu especificamente sobre a difícil situação econômica da autora que dependia, juntamente com seu filho de quatro anos, do parceiro falecido, pois não tinha nenhum tipo de renda nem desfrutava de pensão (Corte Constitucional da Colômbia, Expediente T-6.579.174, p. 23).

A Corte colombiana também invocou os direitos fundamentais à dignidade humana, vida, saúde e igualdade para impedir a interrupção do fornecimento de água em razão do não pagamento por sujeitos sob proteção especial (Corte Constitucional da Colômbia, Sentencia T-740/11, 3 out. 2011). A autora, no caso, era uma mulher de

${ }^{30}$ No original, "protección del derecho fundamental al mínimo vital de las personas en situación de discapacidad o debilidad manifiesta". 
54 anos, chefe de família, incapacitada para o trabalho e responsável por dois filhos menores. Embora a Corte tivesse aplicado a regra legal que permite a suspensão do fornecimento como meio de promover a prestação eficiente, contínua e ininterrupta de serviços públicos a todos, a negativa de água a sujeitos sob proteção especial foi entendida como desproporcional e, portanto, inconstitucional. O tribunal considerou que, em resposta ao inadimplemento, a empresa deveria apurar a situação de crédito do usuário e fazer acordos de pagamento compatíveis com a capacidade concreta de pagamento do usuário. Se ainda assim não for feito o pagamento, a empresa pode limitar o fornecimento de água a 50 litros por usuário (Corte Constitucional da Colômbia, Sentencia T-740/11, 3 out. 2011).

\section{Explicando a divergência}

Nesta seção, passamos a abordar os argumentos em favor da ortodoxia contratual e suas limitações, a fim de buscar compreender a maior prevalência da heterodoxia contratual em países em desenvolvimento.

\section{a. A defesa da ortodoxia}

A visão ortodoxa de que o Direito Contratual não deve ser projetado para atingir objetivos distributivos apoia-se em dois conjuntos principais de argumentos. O primeiro conjunto concentra-se na legitimidade da distribuição pelo Estado, seja para questionar qualquer esforço distributivo pelo Estado (NOZICK, 1974, p. 151-153), seja para restringir as decisões distributivas a representantes eleitos democraticamente, o que não é o caso dos juízes (KORDANA; TABACHNICK, 2005, p. 623-624). O segundo e mais central pilar da ortodoxia do Direito Contratual tem por base a sua efetividade. Afirma-se que a política fiscal por meio da tributação e dos gastos públicos é superior ao Direito Contratual como meio de alcançar a justiça distributiva (KAPLOW; SHAVELL, 1994; RAWLS, 2005, p. 267-268). Pelo menos cinco argumentos distintos apoiam essa perspectiva (WEISBACH, 2003, p. 446-453).

1. Precisão e previsibilidade: As políticas fiscais podem ser condicionadas a informações - como renda das partes, profissão e número de dependentes - que não estão necessariamente disponíveis nem para o juiz de uma disputa contratual, nem para as partes quando celebram o contrato (RAWLS, 2005, p. 101). Isso significa que as regras do Direito Contratual seriam não apenas imprecisas para realizar fins distributivos, mas também levariam a uma incerteza ineficiente entre as partes contratantes. 
2. Abrangência: A distribuição por meio da política fiscal tende a ser mais abrangente (KAPLOW; SHAVELL, 1994, p. 675). Aplica-se a toda a sociedade, e não apenas às partes de um determinado contrato. A distribuição pela via contratual pode parecer um fundamento moralmente arbitrário para determinar quem deve ganhar ou perder com os esforços distributivos do Estado (EISENBERG, 2001, p. 257-258; FRIED, 2015, p. 105-106; POSNER, 1995, p. 284).

3. Eficiência: As regras distributivas de Direito Contratual podem induzir um comportamento ineficiente, no sentido de que seus custos excedam seus benefícios (KAPLOW; SHAVELL, 1994; SHAVELL, 1981). Um exemplo seria o de uma garantia contratual obrigatória cujos custos para os vendedores excedam seus benefícios para os compradores.

4. Evasão: Talvez o argumento mais poderoso contra o uso do Direito Contratual para atingir objetivos distributivos é a possibilidade de as partes evitarem esses efeitos. Isso porque a parte prejudicada pelo objetivo distributivo pode ajustar cláusulas do contrato, como o preço, ou recusar-se completamente a contratar a fim de evitar o efeito distributivo, que varia conforme as particularidades da demanda em cada caso. Por exemplo, se uma determinada intervenção legal é valorizada pelas partes mais vulneráveis, uma consequência possível dessa ingerência é o aumento dos preços, anulando o efeito distributivo desejado (CRASWELL, 1991).

5. Interdependência: Por vezes, o bem-estar das pessoas oneradas por uma intervenção distributiva mostra-se interligado com o bem-estar dos supostos beneficiários, como ocorre quando estes são empregados ou acionistas das companhias que se pretende onerar. Por essa razão, em tese, pode ser difícil determinar os efeitos gerais de uma medida que busca distribuir riqueza de empresas a indivíduos, já que estes podem sofrer se forem seus acionistas ou empregados (CRANE, 2016. Para uma crítica da objeção da interdependência, cf. ELHAUGE, 2016).

Conjugando essas objeções, acrescente-se a ideia de que os juízes possivelmente não apresentam conhecimento técnico necessário para lidar com as preocupações acima mencionadas. No entanto, a falta de especialização judicial parece ser um obstáculo menor se os juízes forem meramente encarregados de implementar regras contratuais distributivas formuladas pelos poderes Legislativo ou Executivo. 


\section{b. Explicando a heterodoxia}

As exigências de distribuição, tal como a relativa legitimidade e eficiência de intervenções judiciais ou fiscais, variam de tempos em tempos e de lugar para lugar. Como Anthony Kronman apontou em artigo clássico (1980, p. 508-510), a defesa da ortodoxia contratual é altamente dependente do contexto social e institucional aplicável. Vários estudiosos norte-americanos reconhecem que outros ramos do Direito (incluindo potencialmente o Direito Contratual) podem servir como um mecanismo second-best para alcançar objetivos distributivos se o sistema fiscal não puder ser utilizado para esse fim (FENNELL; McADAMS, 2016; LISCOW, 2018, p. 1664; MARKOVITS, 2005, p. 556-557, 597-601; McDONNELL, 2003, p. 111).

Nossa hipótese é que a heterodoxia contratual ganha força no Sul Global diante de condições sociais, econômicas e institucionais que se desviam significativamente do ambiente presumido pelas justificativas convencionais da abordagem ortodoxa. Em primeiro lugar, a desigualdade substancial reforça a legitimidade dos esforços liderados pelo Estado para melhorar o bem-estar de grupos desfavorecidos. A desigualdade profunda e a segregação também tornam comparativamente mais fácil direcionar medidas distributivas a atores relativamente privilegiados sem afetar os membros de grupos desfavorecidos.

Na América do Norte, Europa e Ásia, a desigualdade econômica, que há muito constitui tema central em países em desenvolvimento, só recentemente surgiu como motivo de grande preocupação pública (DIXON; SUK, 2018; PIKETTY, 2013). Quando são listados em ordem de seu nível de desigualdade de renda, medida pelo coeficiente de Gini (BANCO MUNDIAL, 2021), os países da África Subsaariana e da América Latina e Caribe ocupam todas as primeiras colocações, com o Brasil e a África do Sul despontando como líderes em desigualdade em suas respectivas regiões (ALVAREDO et al., 2018, p. 10, 40 e 74).

Em segundo lugar, Estados que convivem com altos níveis de desigualdade podem ser incapazes de alcançar fins distributivos apenas mediante instituições fiscais. Por certo, Brasil e a África do Sul se destacam entre os países em desenvolvimento pela magnitude dos esforços distributivos por meio de seus sistemas fiscais, incluindo os gastos públicos com educação e saúde (LUSTIG, 2016). Entretanto, a eficácia de novos incrementos nos gastos públicos pode ser limitada pela capacidade do Estado, permanecendo a desigualdade e a pobreza como problemas sociais altamente relevantes e salientes. 
Em terceiro lugar, países como África do Sul, Colômbia e Brasil são bem conhecidos entre estudiosos de Direito Comparado por adotarem uma abordagem heterodoxa de Direito Constitucional conhecida como "constitucionalismo transformador"31 (MALDONADO, 2013; VILHENA et al., 2013, tradução nossa). O termo foi cunhado para descrever a nova abordagem constitucional da África do Sul e foi subsequentemente aplicado ao Brasil e à Colômbia (KLARE, 1998). Como o rótulo sugere, o constitucionalismo transformador parte da premissa de que o Direito Constitucional deve transformar, e não simplesmente refletir, a sociedade que governa. Seus defensores argumentam que o projeto de transformação social estaria condenado ao fracasso se a desigualdade e a injustiça na esfera privada fossem protegidas de escrutínio. Assim, um preceito chave dessa abordagem é que a Constituição deve ser usada para reformular as leis que regem as relações entre os atores privados, incluindo o Direito Contratual (KLARE, 1998, p. 410-411).

Conquanto se discuta se o constitucionalismo transformador é fenômeno exclusivo de países do Sul Global, tal movimento está nitidamente associado a sociedades que passaram por profundas mudanças políticas (HAILBRONNER, 2017). Nos casos paradigmáticos da África do Sul, da Colômbia e do Brasil, as novas Constituições dos anos 1980 e 1990 foram claramente concebidas para alcançar mudanças econômicas e políticas. Os textos constitucionais dos três países garantem o acesso a direitos sociais fundamentais, como educação, saúde, moradia e segurança social. A ideia central do constitucionalismo transformador contradiz diretamente a ideia de que é ilegítimo para os juízes utilizar o Direito Contratual como ferramenta de distribuição, um fundamento intelectual chave para a ortodoxia contratual.

\section{c. As consequências da heterodoxia}

Nossa análise até este ponto presumiu que a heterodoxia do Direito Contratual é um fenômeno com reais consequências econômicas. Passamos agora a examinar as principais objeções a essa conclusão.

\section{Convergência funcional}

Uma lição clássica de Direito Comparado é que nem todas as diferenças formais entre regras e institutos jurídicos se traduzem em resultados práticos distintos. Ao contrário, célebres comparatistas acreditam que o oposto é verdadeiro, com diferentes rótulos dogmáticos muitas vezes conduzindo a resultados idênticos ou comparáveis,

${ }^{31}$ No original, "transformative constitutionalism". 
ao menos em sistemas jurídicos avançados (ZWEIGERT; KÖTZ, 1998). Cumpre, pois, averiguar se a maior heterodoxia contratual em países em desenvolvimento implica diferenças substanciais na conformação econômica e social.

Sabe-se que pode haver substituição funcional entre diferentes ramos do Direito. Por exemplo, os Estados Unidos (e, em menor grau, outras jurisdições de common law) recorrem frequentemente ao Direito da Insolvência para oferecer um "novo começo" (fresh start) para contratos altamente desvantajosos, ao passo que jurisdições de civil law são mais propensas a oferecer respostas por meio do Direito Contratual (PARGENDLER, 2018). De modo mais geral, o Direito da Insolvência nos EUA oferece espécie de rede de segurança em vista de um Estado social fraco (LAWLESS; WARREN, 2006), tendo atraído uma série de juristas progressistas que visam a objetivos sociais para além da eficiência econômica (SKEEL, 2000). Contudo, embora prevalente, a equivalência funcional não é universal, de modo que a heterodoxia contratual frequentemente produz efeitos econômicos significativos.

\section{Falta de abrangência}

O projeto de confiar no Direito Contratual para alcançar objetivos distributivos pressupõe um grau mínimo de acesso ao mercado e ao Judiciário. Assim, o impacto da heterodoxia contratual fica geralmente limitado às partes que forem capazes de celebrar negócios jurídicos relevantes e que tenham acesso aos tribunais (e às futuras partes em condições semelhantes cujas cláusulas contratuais serão moduladas pela jurisprudência). Os mais pobres dos pobres, porém, frequentemente não têm acesso a negócios relevantes ou ao Judiciário em caso de disputas, em razão não apenas da pobreza, mas também da falta de informações ou outras vulnerabilidades. Consequentemente, os principais beneficiários da heterodoxia contratual tendem a ser os membros da classe média. Crítica semelhante, embora ainda mais grave, é aduzida em relação à judicialização da saúde, que pode ter efeitos regressivos em favor de cidadãos relativamente privilegiados com acesso aos tribunais comparativamente às políticas de saúde pública que beneficiariam os segmentos mais pobres da população (FERRAZ, 2011; PORTUGAL GOUVÊA, 2013; SILVA; TERRAZAS, 2011).

\section{Evasão}

Como vimos, uma crítica central da heterodoxia contratual baseia-se na ideia de que "o tiro pode sair pela culatra". Isto é, as tentativas de favorecer certos grupos em disputas contratuais podem levar a aumentos de preços ou à adoção de outros termos contratuais desfavoráveis que prejudiquem precisamente partes 
semelhantes no futuro (o risco de prejudicar as pessoas que você está tentando ajudar). Os tribunais dos países em desenvolvimento estão cada vez mais cientes dos distintos incentivos ex ante causados pelas decisões sobre o Direito Contratual (PARGENDLER, 2017, 2020a). ${ }^{32}$

Outra preocupação é que a heterodoxia contratual pode impactar a organização industrial e a estrutura do mercado. Ao impor um "imposto de equidade" sobre mecanismos contratuais, o Direito Contratual heterodoxo pode encorajar as empresas a buscarem alternativas aos contratos, como, por exemplo, recorrendo à integração vertical. Um estudo de economistas brasileiros revelou que a rede McDonald's mudou sua estratégia no Brasil, deixando de utilizar principalmente contratos de franquia (como faz na maioria das jurisdições) e passando a operar com uma maioria significativa de lojas próprias (SILVA; AZEVEDO, 2006). A mudança ocorreu depois que os tribunais deixaram de aplicar as cláusulas econômicas dos contratos de franquia em razão das restrições da Lei do Inquilinato, diante de diversas ações pelos franqueados após a desvalorização da moeda em 1999 (SILVA; AZEVEDO, 2006).

Ocorre que o aumento da integração vertical pode não ser um resultado particularmente atraente para países em desenvolvimento cujas economias já são dominadas por grandes grupos empresariais. A literatura aponta que um dos fatores para a prevalência desses grandes grupos em jurisdições em desenvolvimento é justamente a existência de instituições contratuais fracas, de modo que a integração vertical e a reputação da família controladora substituem a execução formal de contratos pelo Judiciário (GILSON, 2007; KHANNA; YAFEH, 2007). Ao enfraquecer a força dos ajustes contratuais, as abordagens heterodoxas podem por vezes erigir barreiras à entrada $\mathrm{e}$ novamente favorecer os grupos empresariais com reputação estabelecida.

\section{Conclusão}

O Direito de alguns países em desenvolvimento, como Brasil, África do Sul e Colômbia, tem apresentado traços comuns e recentes que o distanciam do padrão observado no Norte Global. A maior prevalência da heterodoxia contratual nessas nações lança luz tanto sobre os fatores que influenciam a evolução jurídica no Sul Global como sobre os desafios normativos do Direito Contratual de forma mais geral. Diferentemente da visão convencional, o Direito Privado nos países em desenvolvimento não é sempre uma cópia ou síntese imperfeita de modelos

${ }^{32}$ STJ, REsp 1.426.598, 3a Turma, Rel. Min. Nancy Andrighi, j. 19 out. 2017. 
estrangeiros, tampouco necessariamente moldado por costumes locais antiquados. Os desafios econômicos, sociais e institucionais por eles enfrentados impulsionaram mudanças na aplicação do Direito Contratual, incluindo notavelmente uma maior preocupação com questões distributivas. Embora não esteja claro se essa postura é benéfica, trata-se de fenômeno relevante do ponto de vista econômico.

O surgimento de abordagens jurídicas heterodoxas nos países em desenvolvimento também sublinha a potencial conexão entre a desigualdade e a perda de legitimidade do Direito Contratual ortodoxo. Tanto a crise econômica durante a Grande Depressão como a pandemia da COVID-19 levaram a abordagens comparativamente mais heterodoxas no Direito Contratual de países desenvolvidos. Para aqueles que se opõem à heterodoxia contratual ao sublinhar problemas de ilegitimidade ou incentivos perversos, tal achado pode servir como advertência sobre a importância de mitigar a desigualdade por outros meios para além da tributação e dos gastos públicos. Para aqueles mais simpáticos à heterodoxia contratual, tais experiências concretas apontam para a viabilidade de uma gama mais ampla de ferramentas para combater a injustiça social. Seja como for, o fenômeno revela que a ortodoxia contratual não é tão prevalente ou uniforme como usualmente presumido pela literatura jurídica e econômica.

\section{Referências}

ACKERMAN, Bruce. Regulating slum housing markets on behalf of the poor: of housing codes, housing subsidies and income redistribution policy. Yale Law Journal, v. 80, n. 6, p. 1093-1197, 1971.

AGARWAL, Sumit et al. Regulating consumer financial products: evidence from credit cards. Quarterly Journal of Economics, v. 130, n. 1, p. 111-164, 2015.

AHLERING, Beth; DEAKIN, Simon. Labor regulation, corporate governance, and legal origin: a case of institutional complementarity? Law and Society Review, v. 41, n. 4, p. 865-908, 2007.

ALSTON, Lee J. Farm foreclosure moratorium legislation: a lesson from the past. American Economic Review, v. 74, n. 3, p. 445-457, 1984.

ALVAREDO, Faculdo et al. (coord.). World inequality report 2018. Disponível em: https:// wir2018.wid.world/files/download/wir2018-full-report-english.pdf. Acesso em: 4 fev. 2021.

ARIDA, Persio; BACHA, Edmar Lisboa; LARA-RESENDE, André. Credit, interest, and jurisdictional uncertainty: conjectures on the case of Brazil. In: GIAVAZZI, Francesco et al. (ed.). Inflation targeting, debt, and the brazilian experience, 1999 to 2003. Cambridge: MIT Press, 2005. 
BAGCHI, Aditi. Distributive injustice and private law. Hastings Law Journal, v. 60, n. 1, p. 105-148, 2008.

BAHAMÓN, Gabriela Z. Constitutionalización y protección de derechos fundamentales en el contrato de seguros. Revista Ibero-Latinoamericana de Seguros, v. 25, n. 45, p. 233-268, 2016.

BANCO MUNDIAL. Development Research Group. Gini index. Disponível em: https://data. worldbank.org/indicator/SI.POV.GINI. Acesso em: 19 fev. 2021.

BAR-GILL, Oren; BEN-SHAHAR, Omri. Regulatory techniques in consumer protection: a critique of european consumer contract law. Common Market Law Review, v. 50, n. 1, p. 109-125, 2013.

BARNETT, Randy E. A consent theory of contract. Columbia Law Review, v. 86, n. 2, p. 269-321, 1986.

BENSON, Peter. Justice in transactions: a theory of contract law. Cambridge: Harvard University Press, 2019.

BOTERO, Juan et al. The regulation of labor. The Quarterly Journal of Economics, v. 119, n. 4, p. 1339-1382, 2004.

BRUNOTTE, Nico; ELSAß, Lennart. The German Bundestag resolves amendments to contract law to mitigate the consequences of the coronoavirus crisis, 2020. Disponível em: https://www.lexology.com/library/detail.aspx?g=1c9b4738-ce3f-44df-b5a9-044e449e3b55.

Acesso: 4 fev. 2021.

CARUSO, Daniela. The baby and the bath water: the American critique of European contract law. American Journal of Comparative Law, v. 61, n. 3, p. 479-506, 2013.

CHEREDNYCHENKO; Olha O.; REICH, Norbert. The constitutionalization of European contract law: gateways, constraints and challenges. European Review of Private Law, v. 23, n. 5, p. 797-827, 2015.

COLLINS, Hugh. Distributive justice through contracts. Current Legal Problems, v. 45, n. 2, p. 49-67, 1992.

CRANE, Daniel A. Antitrust and wealth inequality. Cornell Law Review, v. 101, n. 5, p. 1171-1228, 2016.

CRASWELL, Richard. Passing on the costs of legal rules: efficiency and distribution in buyerseller relationships. Stanford Law Review, v. 43, n. 2, p. 361-398, 1991.

DAGAN, Hanoch; HELLER, Michael. The choice theory of contracts. Cambridge: Cambridge University Press, 2017.

DIXON, Rosalind; SUK, Julie. Liberal constitutionalism and economic inequality. The University of Chicago Law Review, v. 85, n. 2, p. 369-401, 2018. 
EISENBERG, Melvin A. The theory of contracts. In: BENSON, Peter (ed.). The theory of contract law: new essays. Cambridge: Cambridge University Press, 2001.

ELHAUGE, Einer. Horizontal shareholding. Harvard Law Review, v. 129, n. 5, p. $1267-1317,2016$.

FALCÃO NETO, Joaquim de Arruda; SCHUARTZ, Luis Fernando; ARGUELHES, Diego Werneck. Jurisdição, incerteza e estado de direito. Revista de Direito Administrativo, v. 243, p. 79-112, 2006.

FENNELL, Lee Anne; McADAMS. The distributive deficit in law and economics. Minnesota Law Review, v. 100, n. 3, p. 1051-1130, 2016.

FERRAZ, Octavio Luiz Motta. Harming the poor through social rights litigation: lessons from Brazil. South Texas Law Review, v. 89, p. 1643-1668, 2011.

FLEMING, Anne. The rise and fall of unconscionability as the 'law of the poor'. Georgetown Law Journal, v. 102, n. 5, p. 1383-1441, 2014.

FRIED, Charles. The ambitions of contract as promise. 2. ed. Nova Iorque: Oxford University Press, 2015.

FRIED, Charles. Contract as promise: a theory of contractual obligation. Cambrige: Harvard University Press, 1981.

FRIEDMAN, Lawrence M. A history of American law. 4. ed. Nova Iorque: Oxford University Press, 2019.

GILSON, Ronald J. Controlling family shareholders in developing countries. Stanford Law Review, v. 60, n. 2, p. 633-656, 2007.

GORDLEY, James. Equality in exchange. California Law Review, v. 69, n. 6, p. 1587-1656, 1981.

HAILBRONNER, Michaela. Transformative constitutionalism: not only in the Global South. American Journal of Comparative Law, v. 65, n. 3, p. 527-565, 2017.

HALL, Peter A.; SOSKICE, David. Varieties of capitalism: the institutional foundations of comparative advantage. Oxford: Oxford University Press, 2001.

HERSHKOFF, Helen. "Just words": common law and the enforcement of state constitutional social rights. Stanford Law Review, v. 62, n. 6, p. 1521-1582, 2010.

HERSHKOFF, Helen. Lecture: the private life of public rights: state constitutions and the common law. New York University Law Review, v. 88, n. 1, p. 1-23, 2013.

HOVENKAMP, Hebert. The first great law \& economics movement. Stanford Law Review, v. 42, n. 4, p. 993-1058, 1990. 
KAPLOW, Louis; SHAVELL, Steven. Why the legal system is less efficient than the income tax in redistributing income. The Journal of Legal Studies, v. 23, n. 2, p. 667-681, 1994.

KENNEDY, Duncan. Distributive and paternalist motives in contract and tort law, with special reference to compulsory terms and unequal bargaining power. Maryland Law Review, v. 41, n. 4, p. 563-658, 1982.

KENNEDY, Duncan. Form and substance in private law adjudication. Harvard Law Review, v. 89, p. $1685-1778,1976$.

KHANNA, Tarun; YAFEH, Yashay. Business groups in emerging markets: paragons or parasites? Journal of Economic Literature, v. 45, n. 2, p. 331-372, 2007.

KLARE, Karl E. Legal culture and transformative constitutionalism. South African Journal on Human Rights, v. 14, n. 1, p. 146-188, 1998.

KORDANA, Kevin A.; TABACHNICK, David. Rawls \& contract law. George Washington Law Review, v. 73, n. 3, p. 598-632, 2005.

KRONMAN, Anthony T. Contract law and distributive justice. Yale Law Journal, v. 89, n. 3, p. 472-512, 1980.

LAMOUNIER, Bolívar; SOUZA, Amaury. As elites brasileiras e o desenvolvimento nacional: fatores de consenso e dissenso: relatório de pesquisa. São Paulo: IDESP, 2002.

LAWLESS, Robert M.; WARREN, Elizabeth. Shrinking the safety net: the 2005 changes in U.S. bankruptcy law, 2006. Disponível em: https://ssrn.com/abstract=949629. Acesso em: 4 fev. 2021.

LISCOW, Zachary. Is efficiency biased? The University of Chicago Law Review, v. 85, n. 7, p. 1649-1718, 2018.

LISCOW, Zachary. Redistribution for realists: working paper, 2020. Disponível em: https://law.yale.edu/sites/default/files/documents/faculty/papers/liscow_-_redistribution_ for_realists_2020-08-03.pdf. Acesso em: 4 fev. 2021.

LISCOW, Zachary. Reducing inequality on the cheap: when legal rule design should incorporate equity as well as efficiency. Yale Law Journal, v. 123, n. 7, p. 2134-2573, 2014.

LUSTIG, Nora. Inequality and fiscal redistribution in middle income countries: Brazil, Chile, Colombia, Indonesia, Mexico, Peru and South Africa. Journal of Globalization and Development, v. 7, n. 1, p. 17-60, 2016.

MALDONALDO, Daniel B. (ed.). Constitutionalism of the Global South: the activist tribunals of India, South Africa and Colombia. Nova Iorque: Cambridge University Press, 2013.

MARKOVITS, Richard S. Why Kaplow and Shavell's "double-distortion argument" articles are wrong. George Mason Law Review, n. v. 13, n. 3, p. 511-619, 2005. 
McDONNELL, Brett H. The economists' new arguments. Minnesota Law Review, v. 88 , p. 86-118, 2003.

NOZICK, Robert. Anarchy, State and utopia. Nova Iorque: Basic Books, 1974.

PARGENDLER, Mariana. Análise econômica e jurídica da "presunção de boa-fé no direito privado brasileiro”. In: YEUNG, Luciana (ed.). Análise econômica do direito: temas contemporâneos. São Paulo: Actual, 2020a.

PARGENDLER, Mariana. Contract law and development: the missing link? The George Washington Law Review, v. 85, n. 6, p. 1717-1738, 2017.

PARGENDLER, Mariana. Controlling shareholders in the twenty-first century: complicating corporate governance beyond agency costs. Journal of Corporation Law, v. 45, p. 953-975, 2020 b.

PARGENDLER, Mariana. The role of the State in contract law: the common-civil law divide. Yale Journal of International Law, v. 43, n. 1, p. 143-189, 2018.

PIKETTY, Thomas. Capital in the twenty-first century. Cambridge: Harvard University Press, 2013.

PINHEIRO, Armando C. Judiciário, reforma e economia: a visão dos magistrados. Rio de Janeiro: IPEA, 2002.

PORTUGAL GOUVÊA, Carlos. Social rights against the poor. Vienna Journal on International Constitutional Law, v. 7, n. 4, p. 454-475, 2013.

POSNER, Eric A. Contract law in the welfare State: a defense of the unconscionability doctrine, usury laws, and related limitations on the freedom to contract. Journal of Legal Studies, v. 24, n. 2, p. 283-319, 1995.

RAWLS, John. Political liberalism: expanded edition. Nova Iorque: Columbia University Press, 2005.

REZENDE, Cristiane L.; ZYLBERSZTAJN, Decio. Pacta sunt servanda versus the social role of contracts: the case of Brazilian agriculture contracts. Revista de Economia e Sociologia Rural, v. 50, n. 2, p. 207-221, 2012.

RIPSTEIN, Arthur. Force and freedom: Kant's legal and political philosophy. Cambridge: Harvard University Press, 2009.

SALAMA, Bruno. Direito do consumidor e decisões bumerangues. Valor Econômico, São Paulo, 13 nov. 2015. Disponível em: https://valor.globo.com/opiniao/coluna/direito-doconsumidor-e-decisoes-bumerangues.ghtml. Acesso em: 12 mar. 2021.

SALAMA, Bruno. Meyerhof. Spread bancário e enforcement contratual: hipótese de causalidade reversa e evidência empírica. Revista Brasileira de Economia, v. 71, v. 1, p. $111-133,2017$. 
SCOTT, Robert E. A joint maximization theory of contract and regulation. In: DAGAN, Hanoch; ZIPURSKY, Benjamin C. (ed.). Research handbook on private law theory. Cheltenham: Edward Elgar, 2020.

SHAVELL, Steven. A note on efficiency v. distributional equity in legal rulemaking: should distributional equity matter given optimal income taxation? American Economic Review, v. 71, n. 2, p. 414-418, 1981.

SILVA, Virgílio Afonso da; TERRAZAS, Fernanda V. Claiming the right to health in Brazilian courts: the exclusion of the already excluded? Law \& Social Inquiry, v. 36, n. 4, p. 825-853, 2011.

SILVA, Vivian Lara dos Santos; AZEVEDO, Paulo Furquim de. Contratos interfirmas em diferentes ambientes institucionais: o caso McDonald's França versus Brasil. Revista de Administração, v. 41, n. 4, p. 381-393, 2006.

SKEEL, David A. Skeel, Jr. Vern countryman and the path of progressive (and populist) bankruptcy scholarship. Harvard Law Review, v. 113, n. 5, p. 1075-1129, 2000.

SPAMANN, Holger. Contemporary legal transplants: legal families and the diffusion of (corporate) law. BYU Law Review, v. 2009, n. 6, p. 1813-1878, 2009.

STUDY GROUP ON SOCIAL JUSTICE IN EUROPEAN PRIVATE LAW. Social justice in European contract law: a manifesto. European Law Journal, v. 10, n. 6, p. 653-674, 2004.

THE AMERICAN LAW INSTITUTE. Restatement of the law consumer contracts tentative draft, 2019. Disponível em: https://www.ali.org/publications/show/consumercontracts/. Acesso em: 4 fev. 2021.

TIMM, Luciano Benetti. Ainda sobre a função social do direito contratual no Código civil brasileiro: justiça distributiva versus eficiência econômica. Revista da AMDE, v. 2, p. 1-40, 2009.

TREBILCOCK, Michael J. The limits of freedom of contract. Cambridge: Harvard University Press, 1993.

TUSHNET, Mark. The inadequacy of judicial enforcement of constitutional rights provisions to rectify economic inequality, and the inevitability of the attempt. In: KHURSHID, Salman et al. (ed.). Judicial review: process, power and problems. Cambridge: Cambridge University Press, 2020.

UNGER, Roberto Mangabeira. The critical legal studies movement. Harvard Law Review, v. 96, p. 561-575, 1983.

VAN LOO, Rory. Broadening consumer law: competition, protection, and distribution. Notre Dame Law Review, v. 95, n. 1, p. 211-261, 2019.

VERSTEEG, Mila. Can rights combat economic inequality? Harvard Law Review, v. 133, p. 2017-2060, 2020. 
VILHENA, Oscar et al. (ed.) Transformative constitutionalism: comparing the apex courts of Brazil, India and South Africa. Joanesburgo: Pretoria University Law Press, 2013.

WEISBACH, David A. Should legal rules be used to redistribute income? University of Chicago Law Review, v. 70, n. 1, p. 439-453, 2003.

WHITMAN, James. The two western cultures of privacy: dignity versus liberty. Yale Law Journal, v. 113, p. 1151-1221, 2004.

WORLD BANK. Doing business 2020: comparing business regulations in 190 economies. Washington: World Bank, 2020.

ZWEIGERT, Konrad; KÖTZ, Hein. An introduction to comparative law. 3. ed. Oxford: Oxford University Press, 1998.

YEUNG, Luciana; AZEVEDO, Paulo Furquim. Nem Robin Hood, nem King John: testando o viés anti-credor e anti-devedor dos magistrados brasileiros. Economic Analysis of Law Review, v. 6, n. 1, p. 1-21, 2015.

\section{Jurisprudência citada}

ÁFRICA DO SUL. Corte Constitucional da África do Sul, Barkhuizen v. Napier [2007] (CCT72/05) ZACC 5. Disponível em: https://www.saflii.org/za/cases/ZACC/2007/5.html. Acesso em: 19 abr. 2021.

ÁFRICA DO SUL. Corte Constitucional da África do Sul, BEADICA 231 CC and Others v. Trustees for the time being of the Oregon Trust and Others (CCT109/19) [2020] ZACC 13. Disponível em: https://www.saflii.org/za/cases/ZACC/2020/13.html. Acesso em: 19 abr. 2021.

ÁFRICA DO SUL. Corte Constitucional da África do Sul, Botha and Another v. Rich NO and Others (CCT 89/13) [2014] ZACC 11. Disponível em: https://www.saflii.org/za/cases/ ZACC/2014/11.html. Acesso em: 19 abr. 2021.

ÁFRICA DO SUL. Corte Constitucional da África do Sul, Everfresh Market Virginia (Pty) Ltd v. Shoprite Checkers (Pty) Ltd (CCT 105/10) [2011] ZACC 30. Disponível em: https://www. saflii.org/za/cases/ZACC/2011/30.html. Acesso em: 19 abr. 2021.

ÁFRICA DO SUL. Corte Constitucional da África do Sul, Paulsen and Another v. Slip Knot Investments 777 (Pty) Limited (CCT 61/14) [2015] ZACC 5. Disponível em: https://www.saflii. org/za/cases/ZACC/2015/5.html. Acesso em: 19 abr. 2021.

ÁFRICA DO SUL. Corte Constitucional da África do Sul, Sarrahwitz v. Maritz N.O. and Another (CCT93/14) [2015] ZACC 14. Disponível em: https://www.saflii.org/za/cases/ ZACC/2015/14.html. Acesso em: 19 abr. 2021. 
ÁFRICA DO SUL. Suprema Corte de Apelação da África do Sul, Trustees for the Time Being of Oregon Trust v. BEADICA 231 CC and Others (74/2018) [2019] ZASCA 29. Disponível em: https://www.saflii.org/za/cases/ZASCA/2019/29.html. Acesso em: 19 abr. 2021.

ÁFRICA DO SUL. Suprema Corte de Apelação da África do Sul, Standard Bank of South Africa Ltd. v. Oneanate Investments (Pty) Ltd (in liquidation) [1997] ZASCA 94. Disponível em: https://www.saflii.org/za/cases/ZASCA/1997/94.html. Acesso em: 19 abr. 2021.

BRASIL. Superior Tribunal de Justiça(3. Turma). Recurso Especial 1.426.598/PR, Relatora: Min. Nancy Andrighi, 19 de outubro de 2017. Disponível em: https://processo.stj.jus.br/ processo/revista/documento/mediado/?componente $=$ ITA\&sequencial $=1573771 \&$ num registro $=201302644675 \&$ data $=20171030 \&$ peticao_numero $=-1 \&$ formato $=$ PDF. Acesso em: 3 jun. 2021.

COLÔMBIA. Corte Constitucional da Colômbia, Sentencia T-027-19, 30 jan. 2019. Disponível em: https://www.corteconstitucional.gov.co/relatoria/2019/T-027-19.htm. Acesso em: 19 abr. 2021.

COLÔMBIA. Corte Constitucional da Colômbia, Sentencia T-724/05, 8 jul. 2005. Disponível em: https://www.corteconstitucional.gov.co/relatoria/2005/T-724-05.htm. Acesso em: 19 abr. 2021.

COLÔMBIA. Corte Constitucional da Colômbia, Sentencia T-740/11, 3 out. 2011. Disponível em: https://www.corteconstitucional.gov.co/relatoria/2011/T-740-11.htm. Acesso em: 19 abr. 2021.

COLÔMBIA. Corte Constitucional da Colômbia, Sentencia T-811-11, 27 out. 2011. Disponível em: https://www.corteconstitucional.gov.co/relatoria/2011/T-811-11.htm. Acesso em: 19 abr. 2021.

ESTADOS UNIDOS DA AMÉRICA. Corte de Apelação do Distrito de Columbia dos Estados Unidos da América, Javins v. First National Realty (428 F.2d. 1071 (D.C. Cir., 1970)). Disponível em: https://www.lexisnexis.com/community/casebrief/p/casebrief-javins-v-first-nat-1realty-corp. Acesso em: 19 abr. 2021.

ESTADOS UNIDOS DA AMÉRICA. Corte de Apelação do Distrito de Columbia dos Estados Unidos da América, Williams v. Walker-Thomas (350 F.2d 445 (D.C. Cir. 1965)). Disponível em: https://www.lexisnexis.com/community/casebrief/p/casebrief-williams-v-walker-thomasfurniture-co. Acesso em: 19 abr. 2021.

ESTADOS UNIDOS DA AMÉRICA. Suprema Corte dos Estados Unidos da América, Home Building \& Loan Ass'n v. Blaisdell, 290 U.S. 398 (1934). Disponível em: https://www.casebriefs. $\mathrm{com} / \mathrm{blog} / \mathrm{law} / \mathrm{constitutional-law/constitutional-law-keyed-to-sullivan/substantive-due-}$ process-rise-decline-revival/home-building-assn-v-blaisdell/. Acesso em: 19 abr. 2021. 


\section{Legislação citada}

ÁFRICA DO SUL. Alienation of Land Act 68 of 1981. [Cape Town]: South African Government, [1998]. Disponível em: https://www.gov.za/documents/alienation-land-act-24mar-2015-1035\#. Acesso em: 19 abr. 2021.

ÁFRICA DO SUL. [Constitution (1996)]. The Constitution of the Republic of South Africa. [Cape Town]: South African Government, [2020]. Disponível em: https://www.gov.za/ documents/constitution-republic-south-africa-1996. Acesso em: 16 abr. 2021.

ÁFRICA DO SUL. National Empowerment Fund Act 105 of 1998. [Cape Town]: South African Government, [2004]. Disponível em: https://www.gov.za/documents/nationalempowerment-fund-act\#. Acesso em: 19 abr. 2021.

ALEMANHA. Gesetz zur Abmilderung der Folgen der COVID-19-Pandemie im Zivil-, Insolvenz- und Strafverfahrensrecht. [Bonn]: Bundesministerium der Justiz und für Verbraucherschutz, [2020]. Bundesgesetzblatt Jahrgang, v. 1, n. 14, mar. 2020. Disponível em: https://www.bmjv.de/SharedDocs/Gesetzgebungsverfahren/Dokumente/Bgbl_CoronaPandemie.pdf?__blob=publicationFile\&v=1. Acesso em: 16 abr. 2021.

COLÔMBIA. [Constitución (1991)]. Constitución Política de Colombia 1991. Bogotá: Corte Constitucional, 2016. Disponível em: https://www.cijc.org/es/NuestrasConstituciones/ COLOMBIA-Constitucion.pdf. Acesso em: 19 abr. 2021. 